\title{
Investigating the Effect of Perceived Organizational Support in Breaking the Organizational Silence with Mediator Role of Affective Commitment on Employees of Governmental Offices in Qom
}

\author{
Ebrahim Rahimi ${ }^{*}$ (D), Vahideh Zaheri $^{2}$
}

1. Assistant Professor and Member of the Technical and Vocational University, Qom Technical and Vocational College, Qom, Iran

2. Master of Public Administration in Human Resource Development Tendency, Delijan Payame Noor University, Delijan, Iran

\begin{tabular}{|c|c|}
\hline Article Info & ABSTRACT \\
\hline $\begin{array}{l}\text { Received: 2020/01/14; } \\
\text { Accepted: 2020/04/29; } \\
\text { ePublished: 2020/07/03 }\end{array}$ & $\begin{array}{l}\text { Background and Objectives: The silence of employees has become a critical } \\
\text { issue for organizational development, referring to deliberate neglect of important } \\
\text { ideas, suggestions and opinions about their work. The purpose of this study was to } \\
\text { investigate the impact of variable organizational support perceived by employees on }\end{array}$ \\
\hline dol $10.30699 /$ jergon.8.1.66 & breaking the silence with the mediating role of emotional commitment. \\
\hline
\end{tabular}

Use your device to scan and read the article online

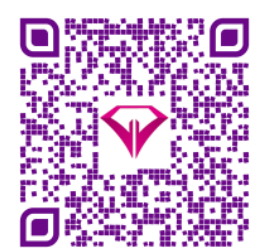

Corresponding Author Ebrahim Rahimi

Assistant Professor and Member of the Technical and Vocational University, Qom Technical and Vocational College, Qom, Iran Email:

Erahimi57@gmail.com
Methods: The statistical population includes 900 governmental employees from Qom city in 2018 which 273 persons have been selected using Cochran formula and random sampling method. Information gathering tools included Eizenberger (1986) perceived organizational support questionnaires, Allen \& Meyer (1990) affective commitment Questionnaire and Silence climate questionnaire of Vakola and Bouradas (2005). After gathering the requested information from the participants, the information was analyzed by Microsoft Excel 2016, SPSS 23.0 and smartpls3.

Results: The results showed that perceived organizational support was positively correlated with employee silence. The results also showed that the emotional commitment mediates the relationship between perceived organizational support and employee silence.

Conclusion: Given the relationship between perceived organizational support and emotional commitment with employee silence, it is essential for planners to consider these components.

Keywords: Affective commitment, Perceived organizational support, Organizational silence

Copyright $\odot$ 2020, This is an original open-access article distributed under the terms of the Creative Commons Attribution-noncommercial 4.0 International License which permits copy and redistribute of the material just in noncommercial usages with proper citation.

\section{How to Cite This Article:}

Rahimi E, Taheri V. Investigating the Effect of Perceived Organizational Support in Breaking the Organizational Silence with Mediator Role of Affective Commitment on Employees of Governmental Offices in Qom. Iran J Ergon. 2020; 8 (1) :66-73 
بررسى تأثير حمايت سازمانى ادراكشده در شكستن سكوت سازمانى با نقش ميانجى تعهد عاطفى (مورد

\section{مطالعه: كاركنان ادارات دولتى شمرستان قم)

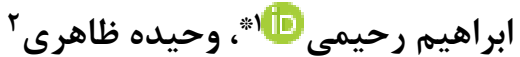

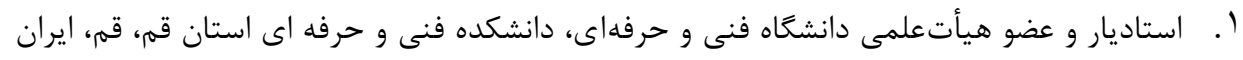

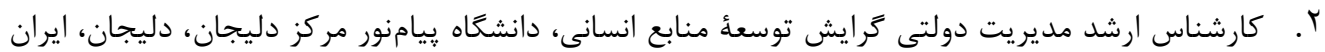

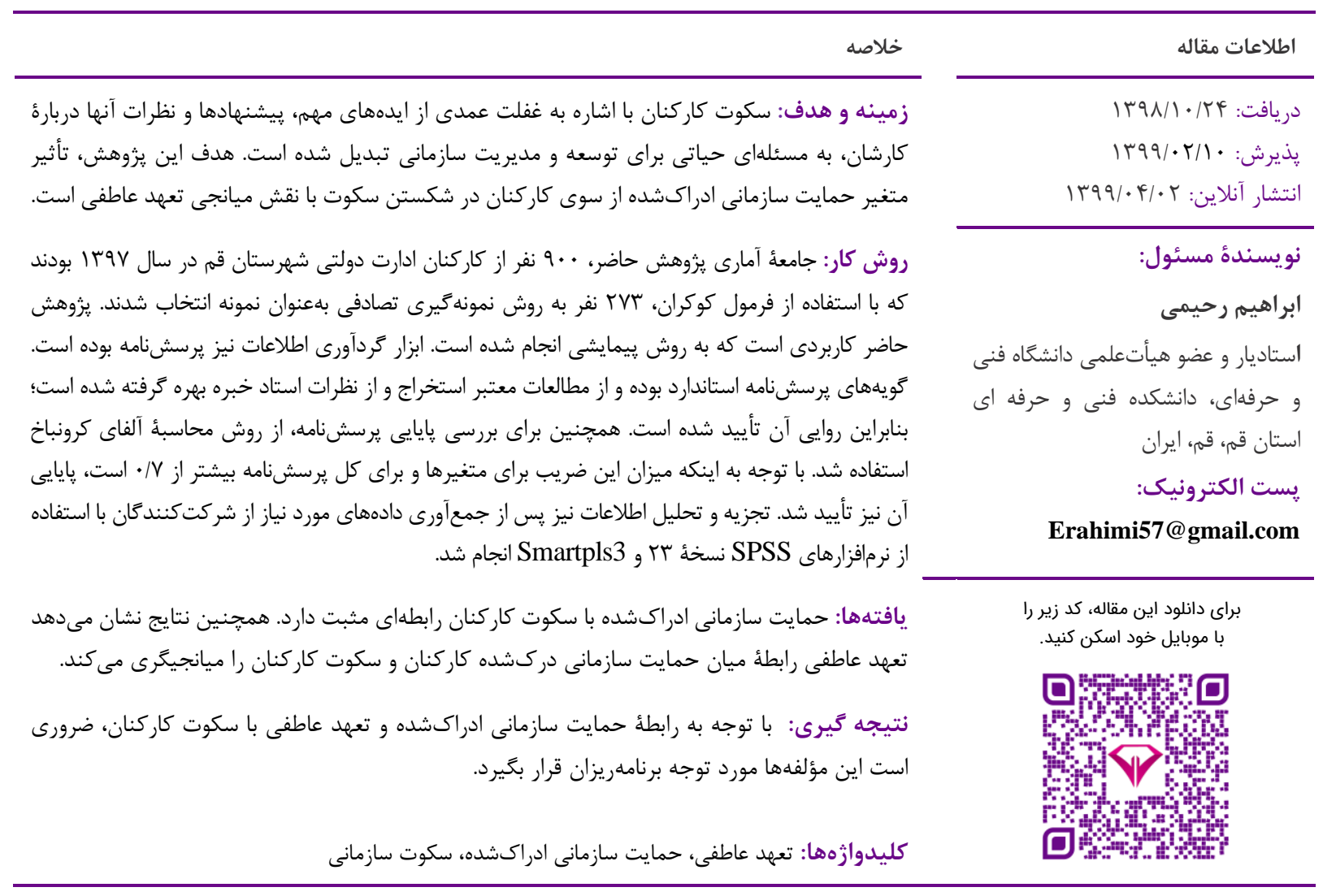

مقدمه

براى سازمانها دارند، ترجيح مىدهند ايدهاى خود را مطرح

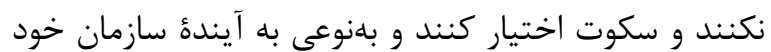

بعى تفاوت باشند [1].

1) Harlos و سكوت كاركنان در سازمان Pinder اخوددارى كاركنان از انتقال اظهارنظرهاى خالصانه و حقيقى خود دربارهٔ اوضاع و احوال و وقايع سازمانى به آنهايى مى دانند كه در جايگاهى قرار دارند كه مىتوانند روى اين شرايط

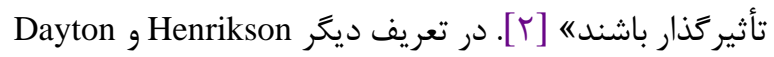
نيز سكوت سازمانى را پديدهاى دستهجمعى تعريف مى كنند كه در آن افراد مشاركت بسيار كمى در واكنش به مسائل و مشكلاتى دارند كه سازمان با آن روبهرو مىشود [ب]. از ديدكاه
در عصر حاضر، سازمانها از كاركنان خود انتظار دارند تا

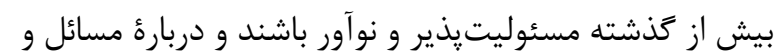
مشكلات سازمانى سخن بكويند. با توجه به فر اهمكردن شرايط

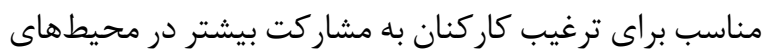

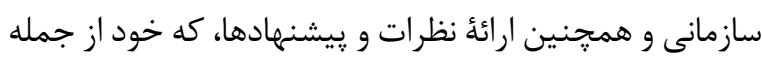
ضرورتهاى حوزه دانش سازمان و مديريت در سالهاى اخير

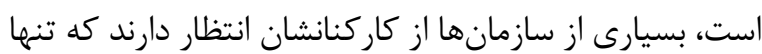

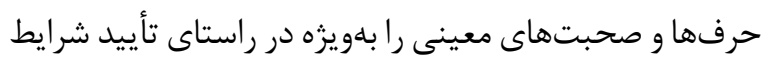
و وضعيت كنونى سازمان بيان كنند؛ براى اين منظور از سازوكارهاى پاداش و تنبيه نيز بهره مىبرند. در جنين

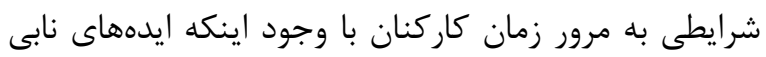


ابراهيم رحيمى و وحيده طاهرى | تأثير حمايت سازمانى ادراكشده در شكستن سكوت سازمانى

ميان، تعهد عاطفى نيز بر سكوت سازمانى تأثير گذار است.

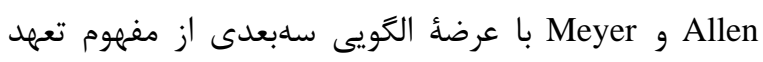

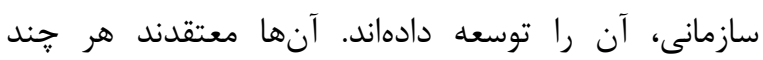

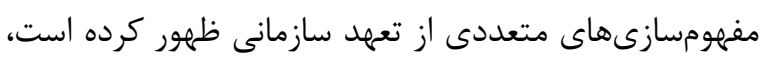

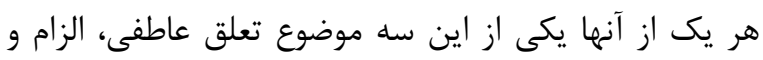

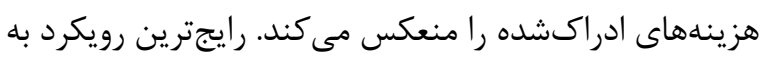

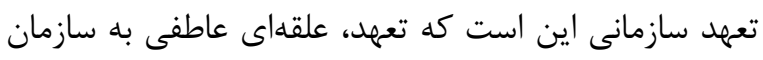

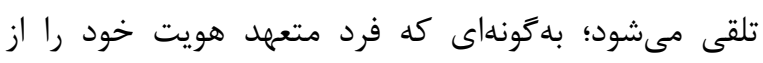

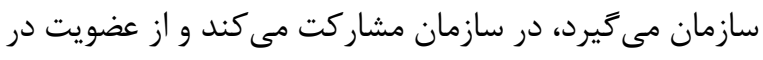

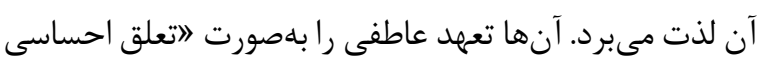

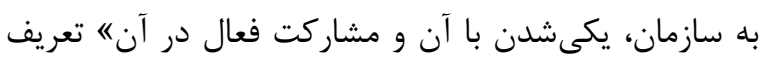

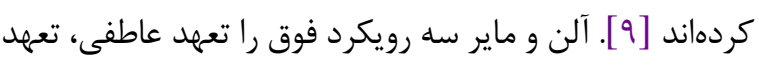

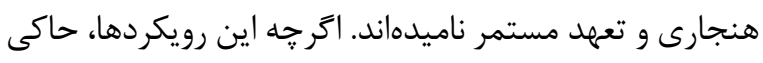

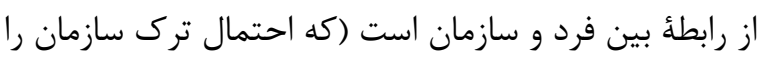

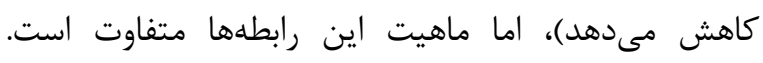

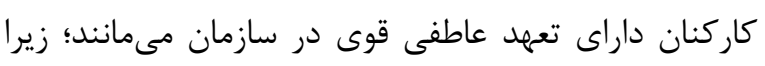

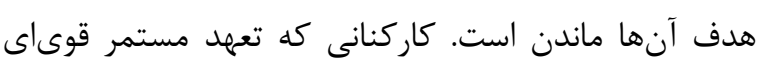

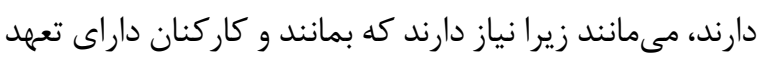

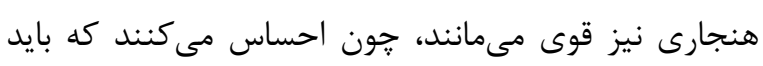

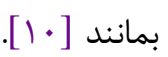

Mayer

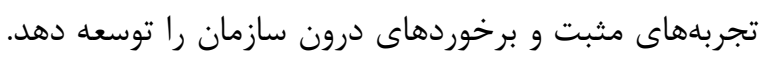

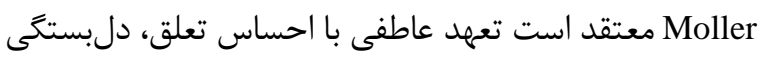

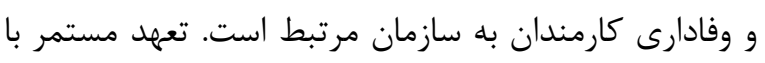

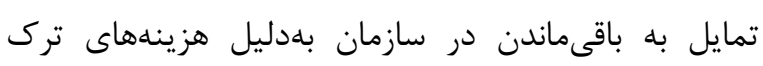

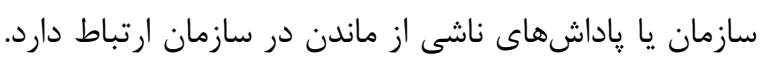

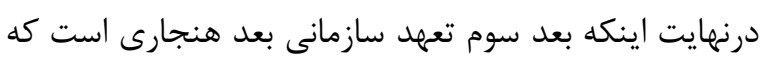

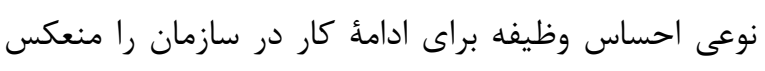

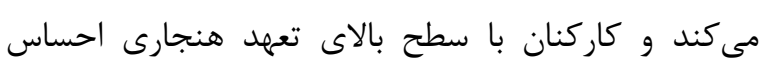

مى كنند كه بايد در سازمان باقى بمانند [11]

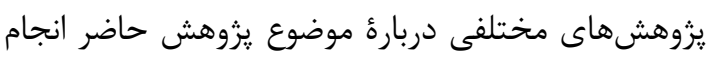

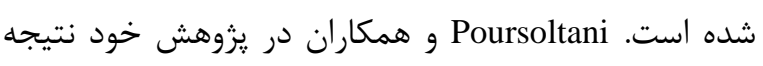

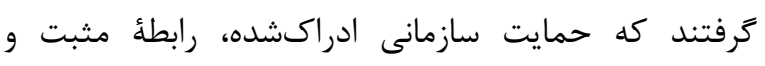

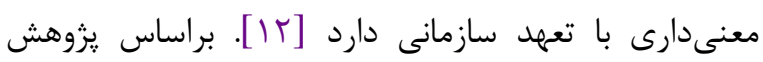
Soori Zehi

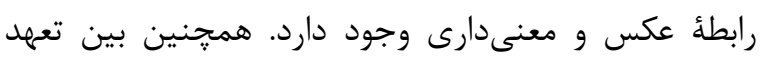

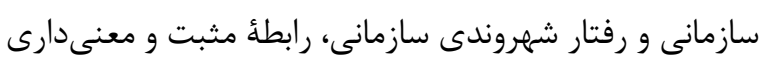

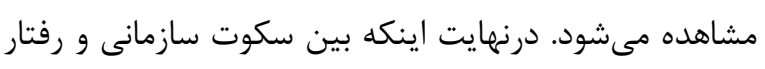

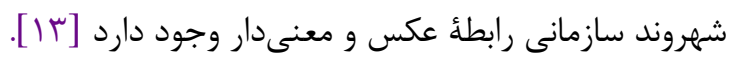

اجتماعى اسكوت سازمانى بديده ساختار يافتهٔ

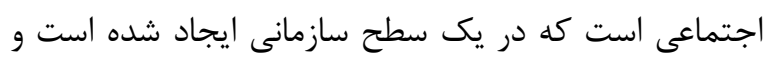

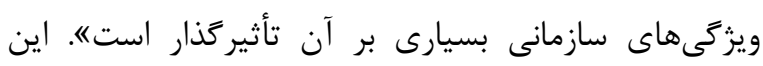

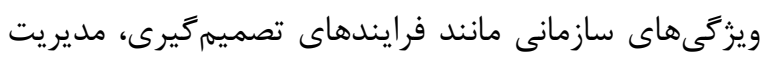

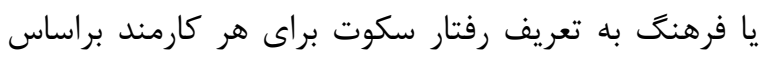

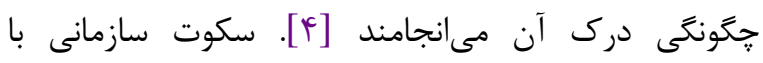

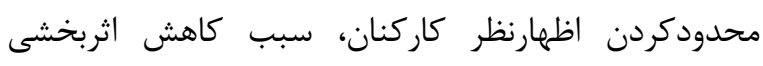

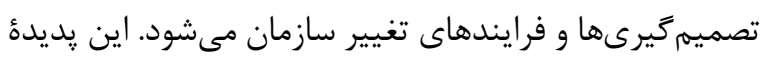

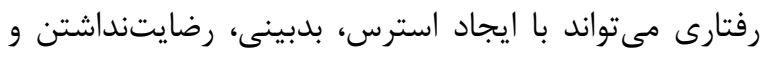

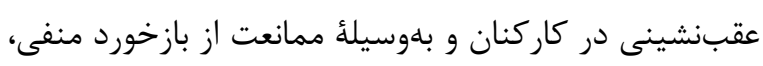

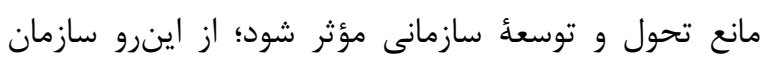

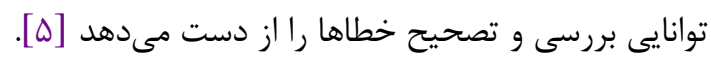

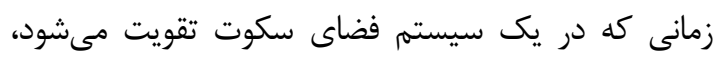

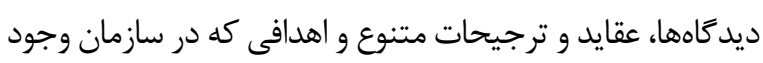

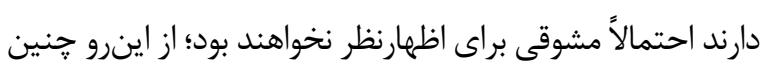

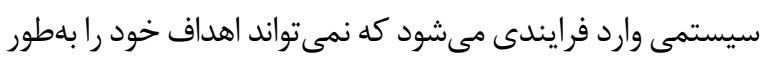

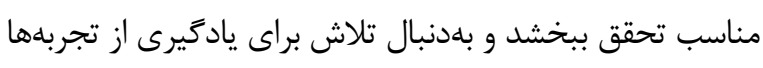

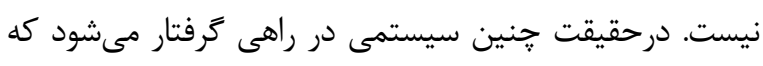

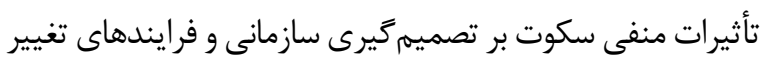

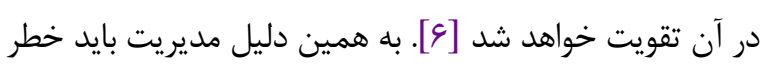

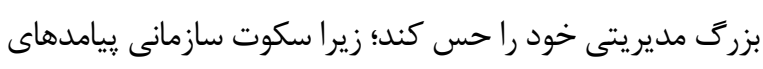
جبران ئذيرى براى سازمان دارد.

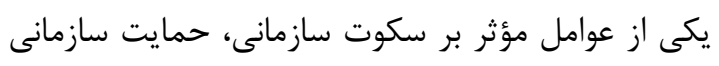

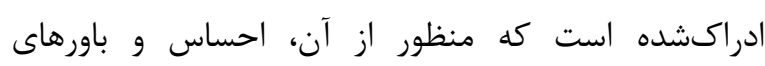

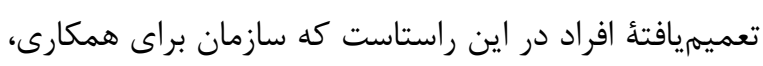

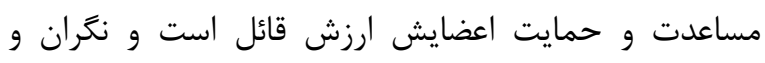

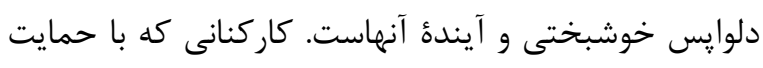

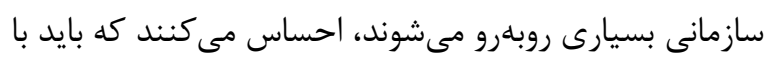

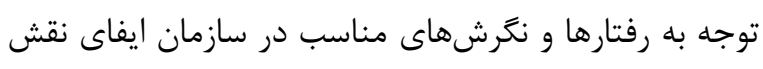

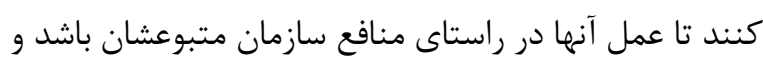

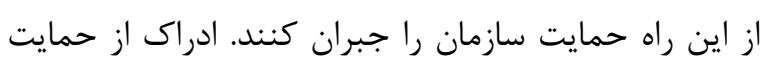

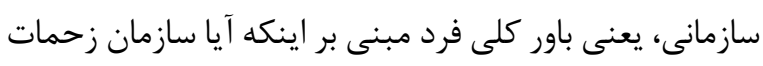

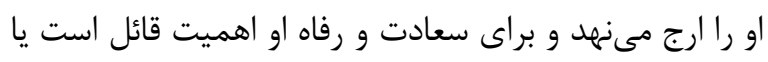
خير [V]

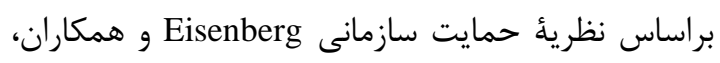

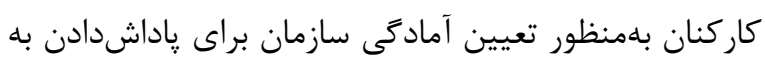

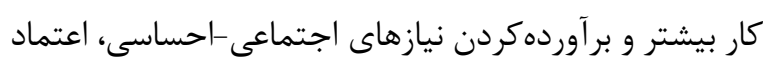

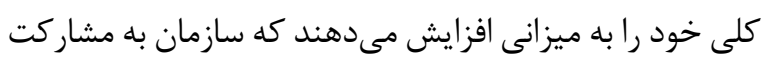

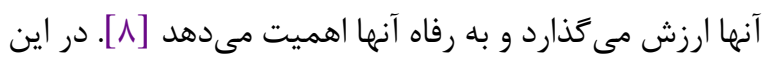


نوآورى يزوهش حاضر را نشان مىدهد. با توجه به هدف يزوهش كه بررسى تأثير متغير حمايت سازمانى ادراكشده از سوى كاركنان در شكستن سكوت با نقش ميانجى تعهد عاطفى است، فرضيههاى يزوهش به شرح زير است:

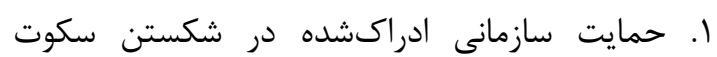

$$
\text { سازمانى تأثير معنى دارى دارد. }
$$

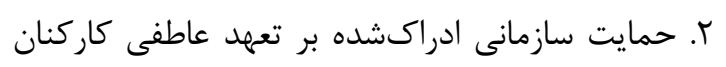
تأثير معنى دارى دارد. r. حمايت سازمانى ادراكشده از طريق تعهد عاطفى درد در شكستن سكوت سازمانى تأثير معنى دارى دارد.

\section{روش كار}

يیزوهش حاضر از نظر هدف كاربردى و از نظر ماهيت و روش توصيفى از نوع همبستگى است. جامعهُ آمارى شامل

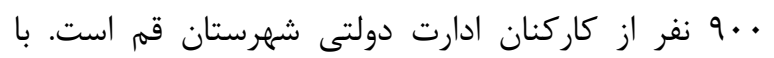
استفاده از فرمول كوكران، · · نفر براى نمونه انتخاب شدند

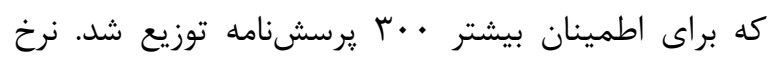

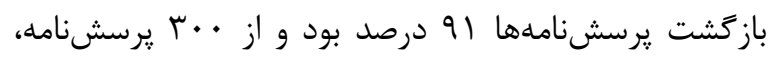
rVT برسشنامه قابلتحليل بازگشت داده شد. بلهمنظور

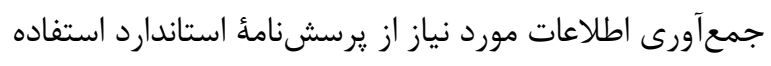
شد. همجنين بامنظور سنجش حمايت سازمانى ادراكشده از

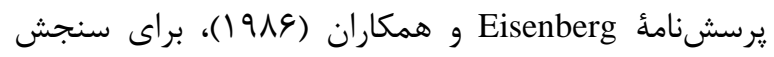
تعهد عاطفى از يرسشنامئ Allen و Meyer ( • (199) و براى هماى سنجش سكوت سازمانى از يرسشنام\& Vakolau و .

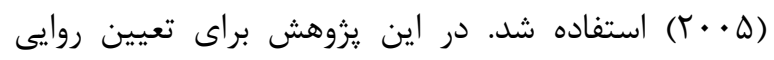

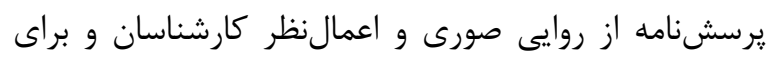

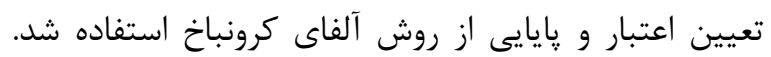
ضريب آلفاى كرونباخ براى متغير حمايت سازمانى ادراكشده

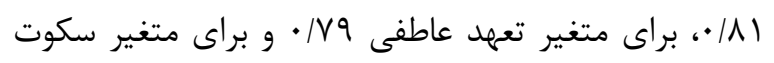

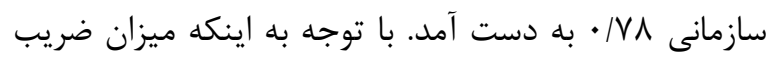

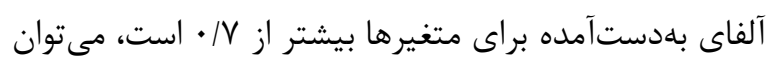

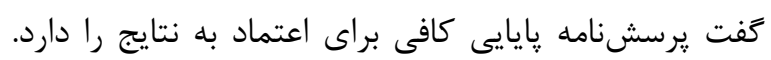

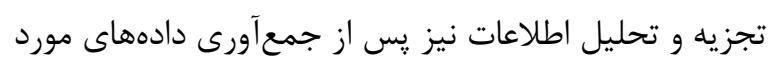

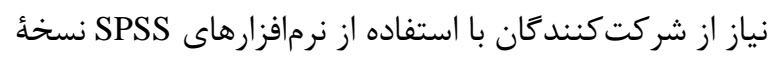

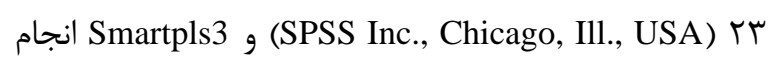
شد. دادهها نيز بهكمك نرمافزار SmartPLS و مدلسازى معادلات ساختارى (SEM) تحليل شدند.
Hadaib Alleyne كرفتند كه اطلاعرسانى داخلى اهداف بهطور فراوانى متأثر از ينج ״يشبينى فردى است (نگرشها، كنترل رفتارى دركشده، تعهد به استقلال، مسئوليت شخصى براى گزارش

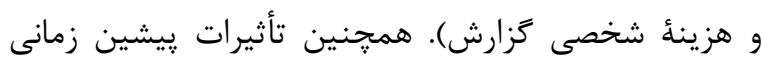
افزايش مىيابد كه سطح حمايت سازمانى ادراكشده بيشتر

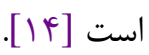

Alvani وجود همبستخى ميان فضاى سكوت دركشده، رفتار همراه با

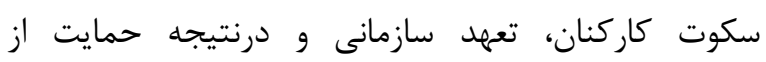
فرضيههاى تحقيق براى هر دو گروه استادان و كاركنان دانشكدههاى علوم انسانى و مديريت، استحكام روابط متفاوت است و ارتباط ميان تعهد و ساير متغيرهاى اين تحقيق براى

استادان قوىتر است [ب].

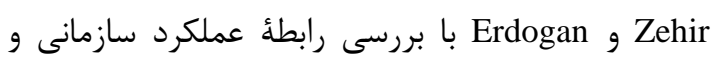

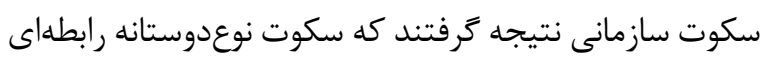

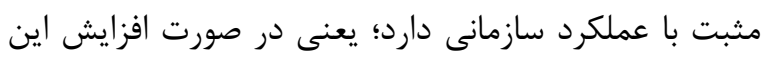
سكوت عملكرد نيز افزايش مىيابد. سكوت مطيع با عملكرد

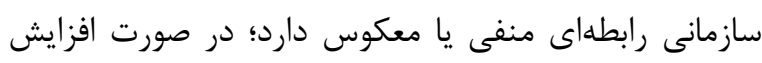
سكوت مطيع، عملكرد سازمانى كاهش مى يابد و هيج ارتباطى مانى

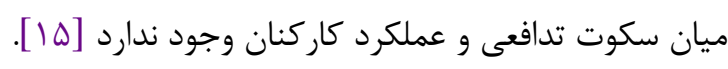
Ozgan تدافعى و عملكرد كاركنان رابطهٔ معنادار منفى و بين سكوت نوعدوستانه و عملكرد كاركنان رابطة مثبت معنادارى وجود ردئ دارد. از سوى ديخر هيج رابطهُ معنادارى بين سكوت مطيع و

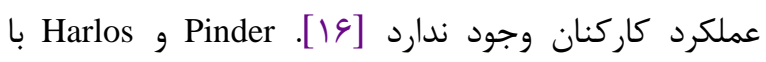
بررسى دلايل سكوت كاركنان در سازمان، انخَيزه افراد را مهرمترين عامل خوددارى از ارائه اطلاعات، ايدهها و نظرات

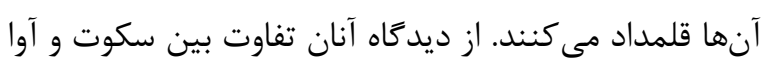
در سخن كفتن نيست، بلكه در انخيزه افراد در خوددارى از ارائٔ

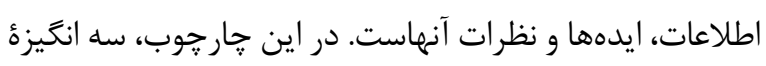

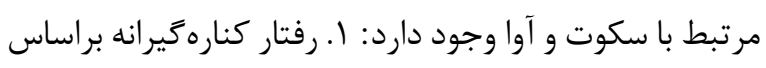

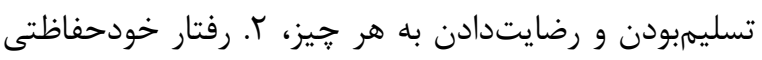
بر اساس ترس، س. رفتارهاى ديخرخواهانه بهدليل علاقه به

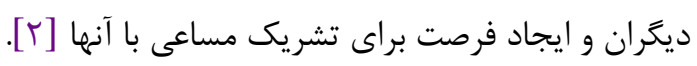

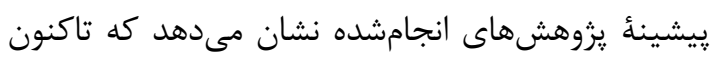
در هيج زيزوهشى به بررسى تأثير متغير حمايت سازمانى

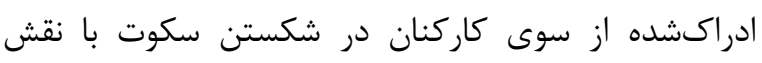
ميانجى تعهد عاطفى توجه نشده است و اين مسئله جنبئ 


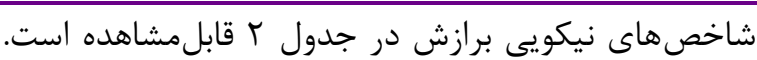

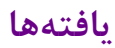

براساس اين شاخصها، مدل برازش دادهشده از مناسبت بلمنظور بررسى روابط ميان متغيرها و برازش مدل از مازئاري

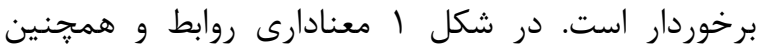
ضرايب ركرسيونى نشان داده شده است.

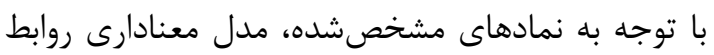

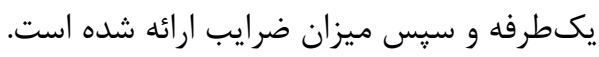

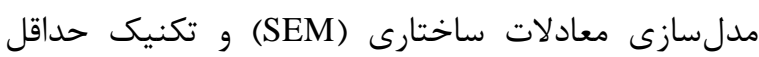
مربعات جزئى (PLS) استفاده شد. نتايج برازش مدل دارئات درات

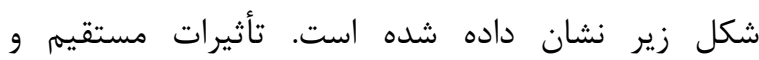

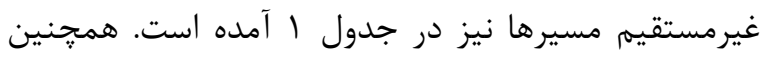

جدول 1. نمادهاى مورد استفاده در مدل

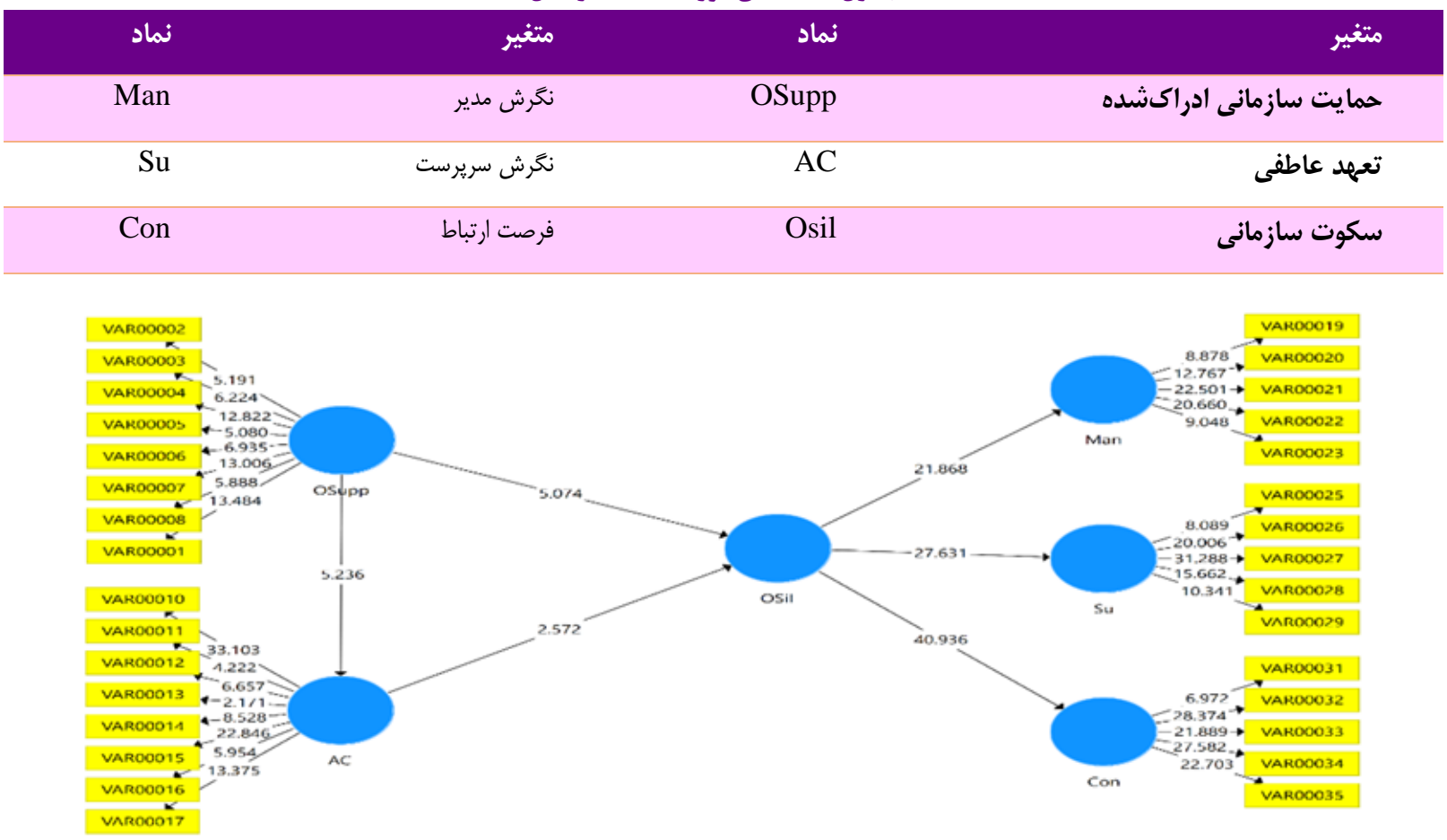

شكل ا. معنادارى t براى بررسى مدل مفهومى (مقادير بزركتتر از 99/ معنىدار در سطح ه+|•)

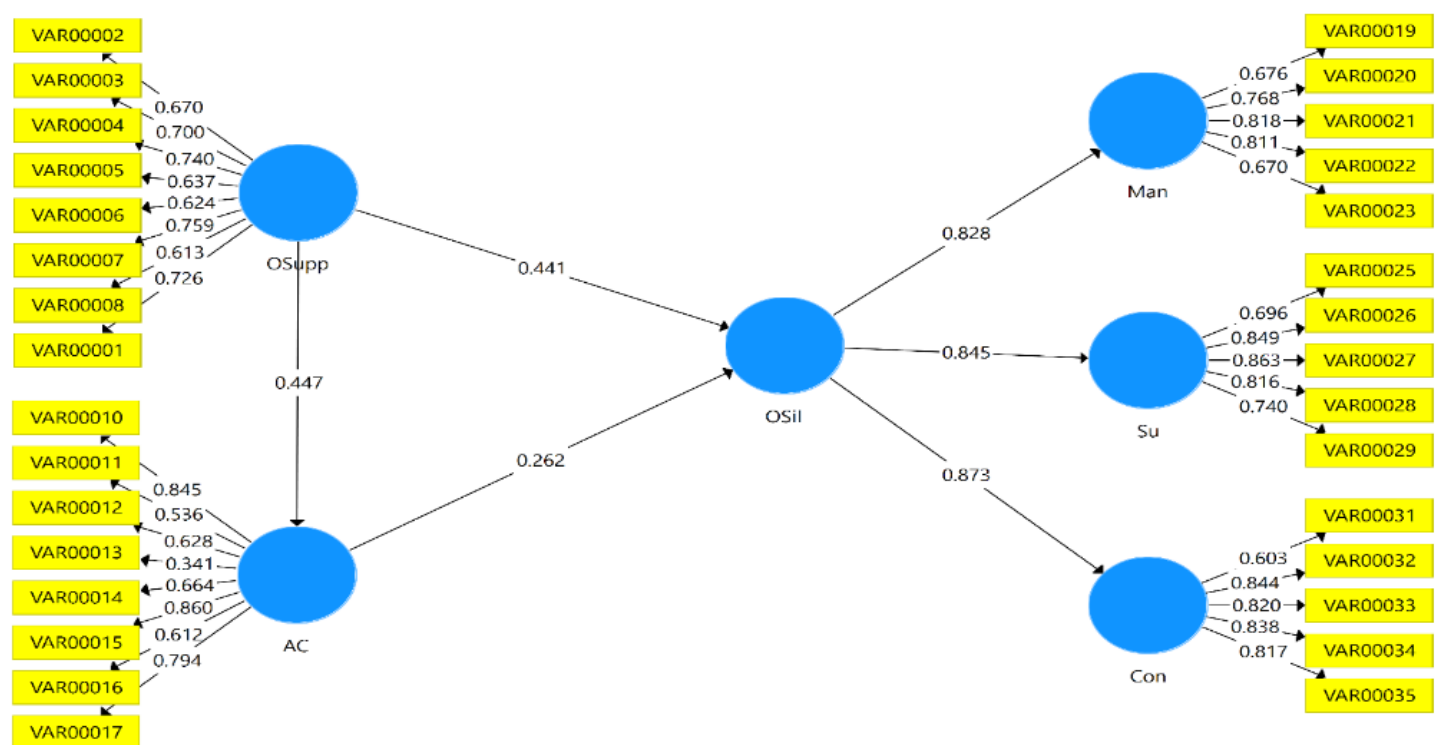

شكل r. مقادير ضر ايب استانداردشده حاصل از مدلسازى معادلات ساختارى براى بررسى مدل مفهومى 


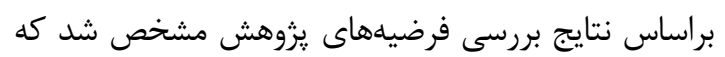

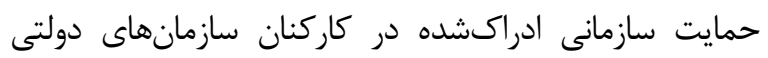
استان قم با در نظر كرفتن نقش ميانجى تعهد عاطفى دانى، تأثير داني

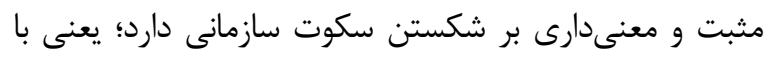
افزايش يك واحد حمايت سازمانى ادراكشده، بهصورت كلى كلى

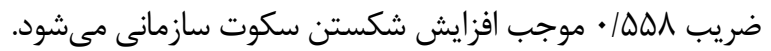

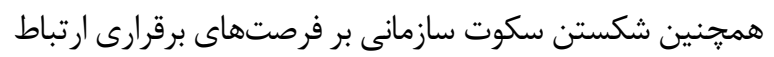

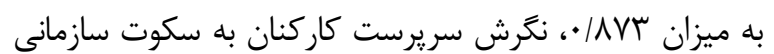

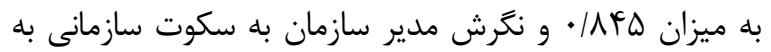

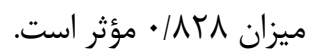

نتايج بهدستآمده در اين شكل نشاندهندة ضرايب ركرسيونى متغيرها بر يكديخر است. براساس نتايج، حمايت

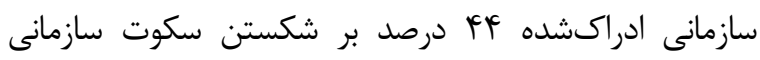

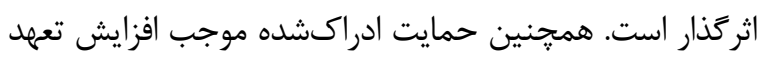

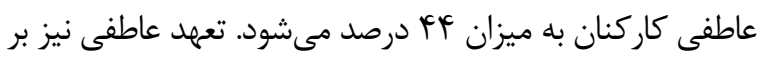

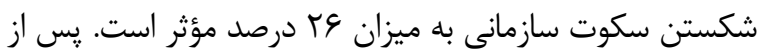
بررسى مدل، شاخصهاى برازش بررسى شدند كه نشان مى دهند

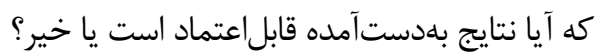
با توجه به نتايج بهدست آمده مشخص مىشود كه رابطؤ بين

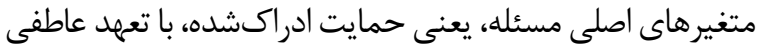

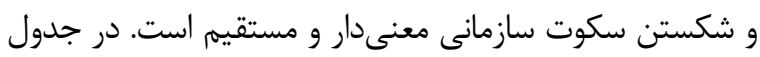
ب برضيههاى تحقيق آمده است.

جدول r. شاخصهاى برازش براى مدل

\begin{tabular}{|c|c|c|c|c|c|c|c|c|}
\hline IFI & NNFI & NFI & CFI & AGFI & GFI & RMSEA & درجهُ آزادى/ كاى دو & شاخص \\
\hline.$/ 91$ &.$/ 94$ &.$/ 91$ &.$/ 94$ & 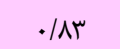 &.$/ 91$ & .1 .94 & r/ו & مقدار محاسبهشده \\
\hline$>.19$. & $>\cdot / 9$. & $>\cdot / 9$. & $>\cdot / 9$. & $>\cdot / \Lambda$. & $>\cdot / 9$. & $<\cdot / 1$ & $<\Delta$ & سطح قابلقبول \\
\hline مناسب & 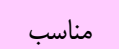 & مناسب & مناسب & مناسب & مناسب & 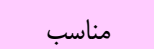 & مناسب & نتيجه \\
\hline
\end{tabular}

\begin{tabular}{|c|c|c|c|c|c|}
\hline ضريب & t مقدار t & متغير وابسته & متخير ميانجى & متغير مستقل & فرضيه \\
\hline$\cdot / \Delta \Delta \Lambda=\cdot /|F F|+\cdot / I I V$ & ---- & شكستن سكوت & تعهد عاطفى & حمايت سازمانى ادراكشده & 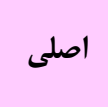 \\
\hline . / FAV & ع عسז/ه & ---- & تعهد عاطفى & حمايت سازمانى ادراكشده & فرعى I \\
\hline$\cdot \mid c 4$ & $\Delta / \cdot V V^{c}$ & شكستن سكوت & ---- & حمايت سازمانى ادراكشده & فرعى r \\
\hline
\end{tabular}

مى دهد كه رابطةٔ مستقيمى بين حمايت سازمانى ادراكشده

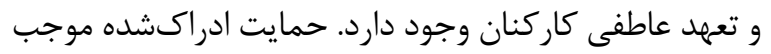

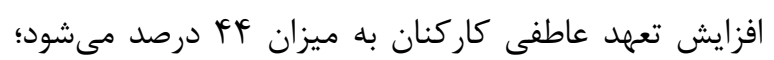
يعنى بيش از FF درصد تغييرات در تعهد عاطفى را مى توان

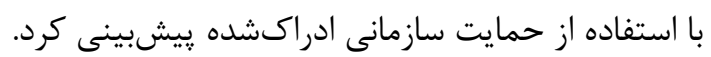
فرضئُ سوم در اين يروهش مربوط به مطالعهُ اثر خذارى و ميزان تأثير حمايت ادراكشده بر شكست سكوت سازمانى از

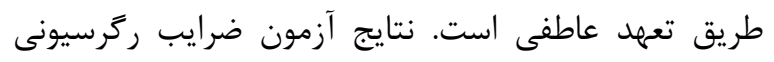
محاسبهشده نشان مى دهد كه در سطح معنى دارى با خطاى كمتر از 1 • • • • كه ميزان قابل قبولى است، ضريب دمدي ركرسيون
يزوهش حاضر با هدف تأثير متغير حمايت سازمانى ادراكشده از سوى كاركنان در شكستن سكوت با نقش بـ ميانجى تعهد عاطفى انجام شد. نتايج آزمون ضريب رَرسيونى محاسبهشده نشان مىدهد كه رابطةٔ مستقيمى در سطح

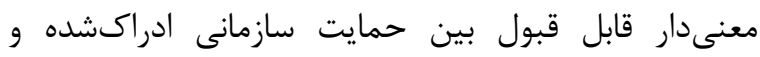
شكستن سكوت سازمانى وجود دارد. براساس نتايج، حمايت

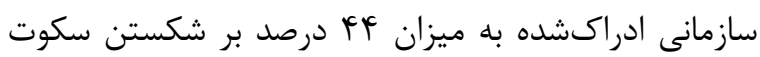
سازمانى اثركذار است؛ يعنى حدود بf لf درصد از تغييرات

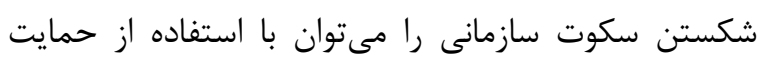
سازمانى ادراكشده پيشبينى كرد. همجنين نتايج نشان 


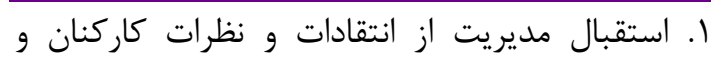

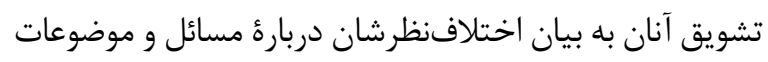

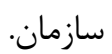
r. توجه به كاركنان و رضايت عمومى آنان و اينكه باور

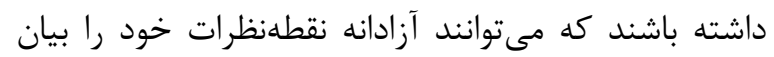

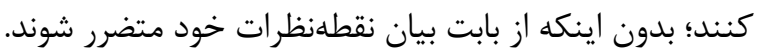

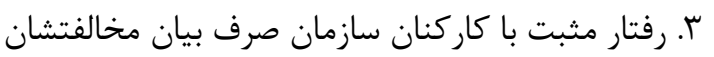

$$
\text { درمورد مسائل سازمان از سوى مديريت. }
$$

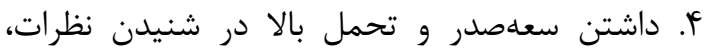

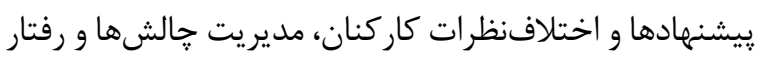

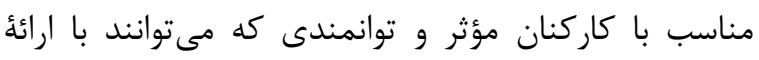

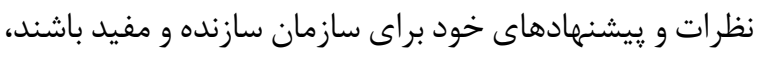

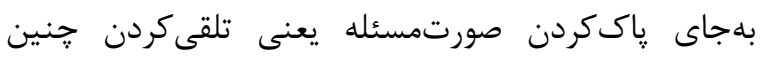
كار كنانى بهعنوان كار كنان معترض وض و و حاشيهدار.

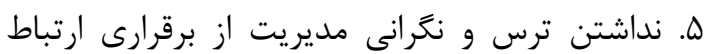

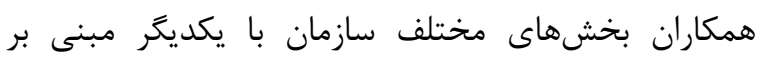

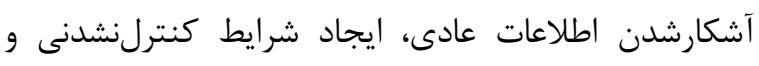
ناتوانى در קاسخكًويى. 9. ايجاد كانالهاى ارتباطى مناسئ مناسب ميان كاركنان و و

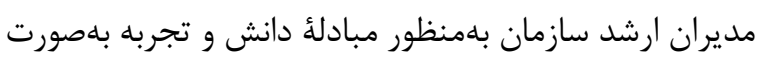
سازمانيافته و منظمه ميان كاركنان.

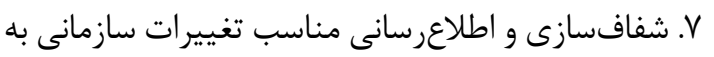
كاركنان و آكاهسازى آنان از مأموريت، برنامهها و و رونداند

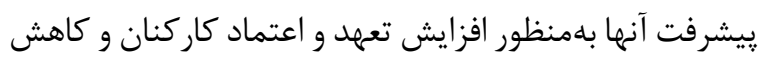
زمينٔ سوءاستفاده و مقابله با رانت اطلاعاتى. 1. تسهيل رويههاى نظام بيشنهادهاى.

\section{تقدير و تشكر}

نويسندكان از همأ كسانى كه آنها را در انجام اين يزوهش يارى كردهاند، كمال تشكر و قدردانى را دارند.

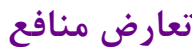

بين نويسندًان هيجَّونه تعارضى در منافع وجود ندارد.

$$
\text { منابع مالى }
$$

منابع مالى اين مطالعه توسط نويسندكان تامين شده است.

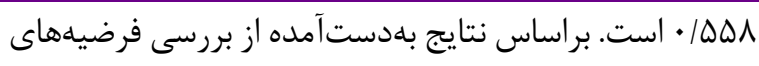
يزوهش مشخص شد كه حمايت سازمانى ادراكشده در دران

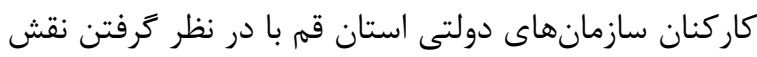
ميانجى تعهد عاطفى بر شكستن سكوت سازمانى تأثير مثبت

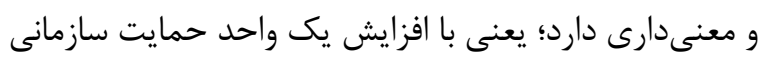

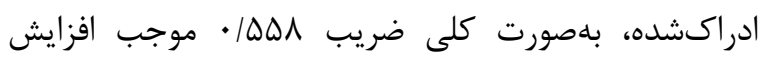

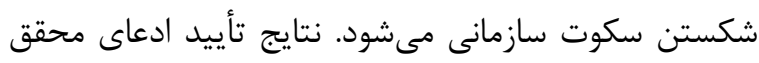
در اين تحقيق با نتايج بلهدستآمده از مطالعات

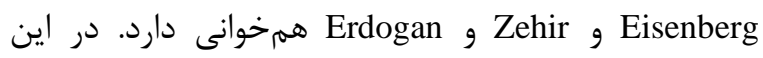
مطالعات رابطؤ حمايت سازمانى و شكست سكوت سازمانى تأييد شده است. نتايج بهدست آمده مبنى بر اثركذاربودن حمايت سازمانى

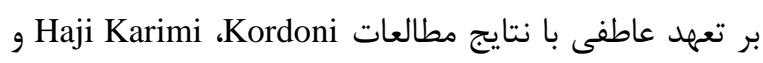

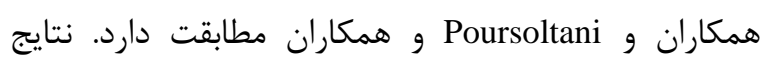
بهدستآمده مبنى بر اثر كذاربودن حمايت سازمانى ادراكشده

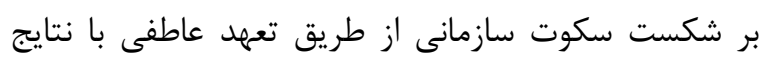

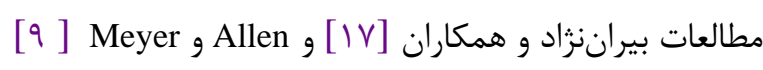

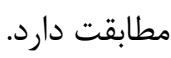

\section{نتيجه كيرى}

نتايج بلهدستآمده نشان مى دهد كه هر سه فرضيأ محقق تأييد شده است؛ بدينترتيب كه بر مبناى فرضيأ اول، حمايت

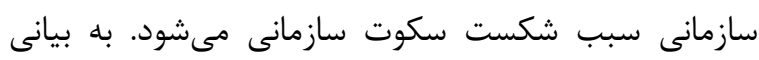

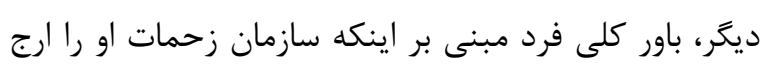

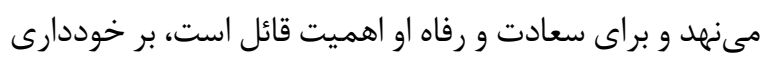

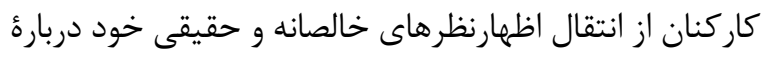

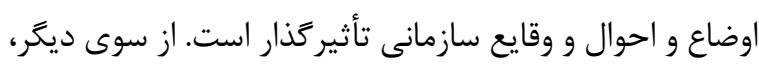

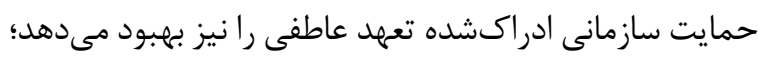

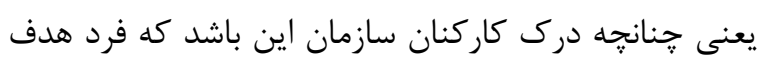

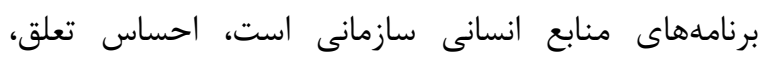

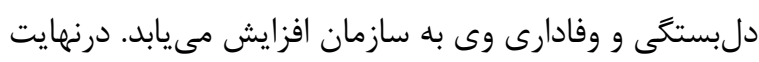

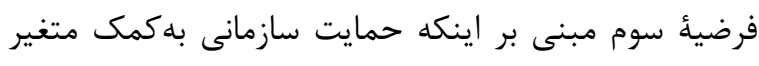
ميانجى تعهد عاطفى بر شكست سكوت سازمانى اثر مى كذارد، تأييد شده است.

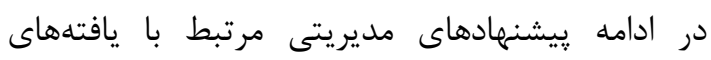

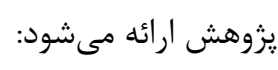




\section{References}

1. Poursoltani, H., Aghaei, N., \& Asgari, B., (2016), Relationship perceived organizational support with Organizational commitment among staff, Sports Management Studies, Volume 8, Issue 35. Pp. 198-183, https://smrj.ssrc.ac.ir/issue_151_152_.html.

2. Pinder CC, Harlos KP. Employee silence: Quiescence and acquiescence as responses to perceived injustice. Research in personnel and human resources management. 2001 Mar;20:331-70. [DOI:10.1016/S07427301(01)20007-3]

3. Nikmaram S, Yamchi HG, Shojaii S, Zahrani MA, Alvani SM. Study on relationship between organizational silence and commitment in Iran. World Applied Sciences Journal. 2012;17(10):1271-7.

4. Morrison EW, Milliken FJ. Organizational silence: A barrier to change and development in a pluralistic world. Academy of Management review. 2000 Oct 1;25(4):70625. [DOI:10.5465/amr.2000.3707697]

5. Zarei Matin, Hassan, Taheri, Fatemeh and Sayar, Abolghasem. (2012). Organizational silence: concepts, antecedents, and consequences, Iranian journal of management sciences (IAMS). Volume \& Issue: Volume 6, Number 21, Pages 77-104.. http://journal.iams.ir/issue_25_28.html

6. Duncan R. Organizational learning: Implications for organizational design. Research in organizational behavior. 1979;1:75-123.

7. Haji Karimi, A., Rezaian, A., Hadizade Moghaddam, A., Bonyadi Na'ini, A. (2011). A Study of Emotional, Social and Cognitive Intelligence Competencies Effect on Iranian Public Sector Human Resource Manager., Strategic Management Thought, Volume 5, Issue 1 Pages 223-254 http://smt.journals.isu.ac.ir/issue_30_37.html

8. Rhoades L, Eisenberger R, Armeli S. Affective commitment to the organization: The contribution of perceived organizational support. Journal of applied psychology. 2001 Oct;86(5):825. [DOI:10.1037/00219010.86.5.825] [PMID]

9. Allen NJ, Meyer JP. The measurement and antecedents of affective, continuance and normative commitment to the organization. Journal of occupational psychology. 1990 Mar;63(1):1-8. 8325.1990.tb00506.x]

[DOI:10.1111/j.2044-

10. Hamid SF, Nordin N, Adnan AA, Sirun N. A study on primary school teachers' organizational commitment and psychological empowerment in the district of klang. Procedia-Social and Behavioral Sciences. 2013 Oct 10;90:782-7. [DOI:10.1016/j.sbspro.2013.07.152]

11. Michael O, Petal P. Job stress and organizational commitment among mentoring coordinators. International Journal of Educational Management. 2009 Mar 27. [DOI:10.1108/09513540910941766]

12. Lew $\mathrm{T}$. The relationships between perceived organizational support, felt obligation, affective organizational commitment and turnover intention of academics working with private higher educational institutions in Malaysia. European Journal of Social Sciences. 2009;9(1):72-87.

13. Çınar O, Karcıoğlu F, Alioğulları ZD. The relationship between organizational silence and organizational citizenship behavior: a survey study in the province of Erzurum, Turkey. Procedia-Social and Behavioral Sciences. $2013 \quad$ Nov 6;99:314-21. [DOI:10.1016/j.sbspro.2013.10.499]

14. Alleyne P, Hudaib M, Haniffa R. The moderating role of perceived organisational support in breaking the silence of public accountants. Journal of Business Ethics. $2018 \mathrm{Feb}$ 1;147(3):509-27. [DOI:10.1007/s10551-015-2946-0]

15. Zehir C, Erdogan E. The association between organizational silence and ethical leadership through employee performance. Procedia-Social and Behavioral Sciences. 2011 Jan 1;24:1389-404. [DOI:10.1016/j.sbspro.2011.09.054]

16. Ozgan H. The Relationships between Organizational Justice, Confidence, Commitment, and Evaluating the Manager and the Perceptions of Conflict Management at the Context of Organizational Behavior. Educational Sciences: Theory and Practice. 2011;11(1):241-7.

17. beyran nejadm A., \& davari, E., \& afkhami, M. (2017). Organizational silence as a Current Challenge in Human Resource Management: Exploring the Factors and Consequences, Organizational Behavior Studies, Volume 6, Issue 1, Pages 147-176. http://obs.sinaweb.net/issue_4265_4266.html. 